MATEC Web of Conferences 48,06006 (2016)

DOI: $10.1051 /$ matecconf $/ 20164806006$

(C) Owned by the authors, published by EDP Sciences, 2016

\title{
Problem-based teaching in engineering education
}

\author{
Marina Kuimova $^{1, a}$, Douglas Burleigh ${ }^{2}$ and Anastasiya Trofimova ${ }^{1}$ \\ ${ }^{1}$ National Research Tomsk Polytechnic University, 634050 Tomsk, Russia \\ ${ }^{2}$ La Jolla Cove Consulting, 92117 San Diego CA, USA
}

\begin{abstract}
The aerospace industry requires highly educated, motivated engineers capable of working with increasingly complex processes and equipment, rapidly-changing requirements, and the need to constantly improve production efficiency. Colleges and universities throughout the world strive to provide training to young professionals for jobs in high-tech industries and to provide not only core technical knowledge, but also training on how to approach problems creatively and to generate novel solutions to problems. Problem-based learning (PBL) contributes to solving this problem. This paper reviews the literature on PBL, studies its benefits and drawbacks, and presents the positive results achieved by its implementation in the training of engineering students at Tomsk Polytechnic University.
\end{abstract}

\section{Introduction}

The traditional educational paradigm no longer meets the requirements of modern industry. The main reasons for this are the acceleration of social development, the changing situation in the labor market, and a decrease in formalization. Employers now expect more from job candidates to than just specialized education. Prospective employees have to be technically competent, resourceful, and independent to be competitive in the labor market. To satisfy the needs of business and industry, engineering universities must introduce innovative teaching methods and approaches in their curricula, and PBL (problem-based learning) is one of them.

Engineering universities strive to create a learning process that promotes self-education and selfdevelopment, and develops professional competence and creative skills. Creativity is required when students must face problems they have not learned in their education and need to find a way to solve these problems. PBL is a creative process that helps to develop skills for solving non-standard educational and scientific tasks. In the literature, PBL is described differently. We support the definition given by D. Boud \& G. Feletti: "Problem-based learning is an approach to structuring the curriculum which involves confronting students with problems from practice which provide a stimulus for learning" [1]. In PBL, a teacher does not provide students with information on a particular issue, but organizes learning situations in which students solve problems and obtain new knowledge. It is a motivating and challenging approach, which has both followers and opponents. Supporters of PBL state that it enhances learning outcomes and:

- Allows learning by other than formal means;

- Teaches students to identify and search for needed knowledge,

${ }^{\mathrm{a} C}$ Corresponding author : mkuimova@mail.ru

This is an Open Access article distributed under the terms of the Creative Commons Attribution License 4.0, which permits unrestricted use, distribution, and reproduction in any medium, provided the original work is properly cited. 


\section{MATEC Web of Conferences}

- Provides meaningful context for knowledge;

- Promotes the abilities and skills to apply knowledge to new or unfamiliar situations;

- Encourages students to think deeply and independently, rather than just memorize facts;

- Develops problem-solving skills as well as self-directed learning skills;

- Improves interpersonal skills;

- Promotes creativity and independence;

- Promotes life-long learning [2-6].

Others believe that PBL may be less effective than traditional methods because it:

- Develops problem-solving skills at the expense of acquiring standard knowledge;

- Is inappropriate for beginners, as it requires a certain level of background knowledge;

- Requires time to find a solution to a problem;

- Does not provide a hierarchical list of topics;

- Makes monitoring and assessment difficult [7-10].

PBL empowers learners to conduct research, integrate theory with practice, and take responsibility for their own learning [11]. PBL is applied in a variety of educational institutions (medicine, architecture, engineering, business administration, law, psychology, nursing, etc.) and is integrated into a wide range of disciplines. In foreign language education, PBL helps learners acquire linguistic competence, develop abstract and situation-specific thinking, provokes reasoning, and trains students to solve unconventional tasks [12]. The purpose of this study is to examine the benefits of the implementation of PBL in teaching English as a foreign language in a university.

\section{Discussion and research}

The primary goal of PBL is to enhance learning by requiring students to identify and solve problems of a particular discipline. Problems are used as tools to acquire required knowledge. Learning occurs in small student groups. [13]. As a pedagogical tool, PBL helps solve a variety of educational tasks. It:

- Provides motivation to learn;

- Increases cognitive interest in educational and professional issues;

- Strengthens the retention of learned material;

- Promotes the independence of learners;

- Develops research skills;

- Develops creative abilities;

- Develops communicative competence [14-21].

PBL may be applied to a real problem (theoretical or practical issue) in a particular discipline. Students are introduced to the problem before they have learned the required knowledge. They work together to identify the learning requirements. It stimulates knowledge building, study and learning how reach a solution to a problem. Problems and learning situations must be carefully sequenced to ensure that students are taken through the syllabus. When selecting problems and learning situations, it is important to make sure that they are:

- Consistent with the syllabus;

- Clearly defined;

- Challenging, but possible to solve;

- Appropriate to the students' level of knowledge, intellectual abilities and interests.

A problem should be meaningful, and it should promote ideas and knowledge sharing. A problem should apply to science, a profession, or the learning process. It should also motivate students to find a solution to the problem, to perform research, and to recognize the possibility of ambiguous solutions. Students should also learn that there is rarely a unique approach to an investigation; there may be many.

The creation of a problem includes the following stages:

- Selection of educational material;

- Selection of questions and conditions that may evoke contradiction; 
- Discussion of possible approaches to solve the contradiction.

In PBL, small student groups work on problem-based tasks. A teacher generally facilitates the learning process by guiding students, keeping them focused on the task, and stimulating interest, thought and discussion. The teacher also provides the educational materials, organizes the learning process, creates a stimulating learning environment, promotes the engagement of the whole group in discussions, and challenges the students to think creatively. In addition, the teacher monitors and assesses progress, and comments and summarizes progress. However, the teacher does not "teach" in the traditional way. The problem-solving competencies of the students are assessed with such techniques as case-study, self- and peer assessment, performance-based assessment, and the final report.

In general, the PBL process includes the following stages:

- Reading the task and defining the problem;

- Brainstorming possible solutions;

- Arrange explanations and define the learning objectives needed to test/prove the validation of assumptions and hypotheses;

- Study available information resources;

- Share the results of the study with the group.

To evaluate the effectiveness of PBL, we created two groups of students, each consisting of sixteen fourth-year students studying English for Electrical Engineering at National Research Tomsk Polytechnic University (TPU). One group was a "control" and the other was the experimental group. For the whole semester, the students of the control group were taught using traditional methods and the students of the experimental group were taught using PBL. At the end of the semester, all of the students were asked about their attitudes on their experience with the program, and they were asked to indicate on a scale from 1-6 (where 1 is the highest mark) their preference for the form of work in their classes:

1. Individual (independent) work;

2. Teacher-centric activities;

3. Pair work;

4. Group work;

5. Research work;

6. Discussions.

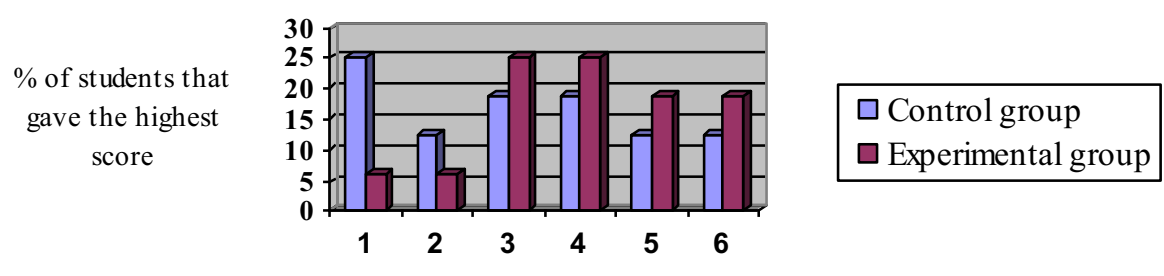

Forms of work

Figure 1. Student preferences for the forms of work in classes.

An analysis of the study on the forms of work used in classes has shown that students in the experimental group prefer innovative methods (pair work, group work, research work, discussions).

At the beginning, middle and end of the semester, the students of both groups performed assessment tasks. The groups were given the same tests. The results of the tests are presented on the histogram in Figure 2. The Y-axis shows the average grade received by the group (10 was the maximum score), and the $\mathrm{X}$-axis shows which test. 


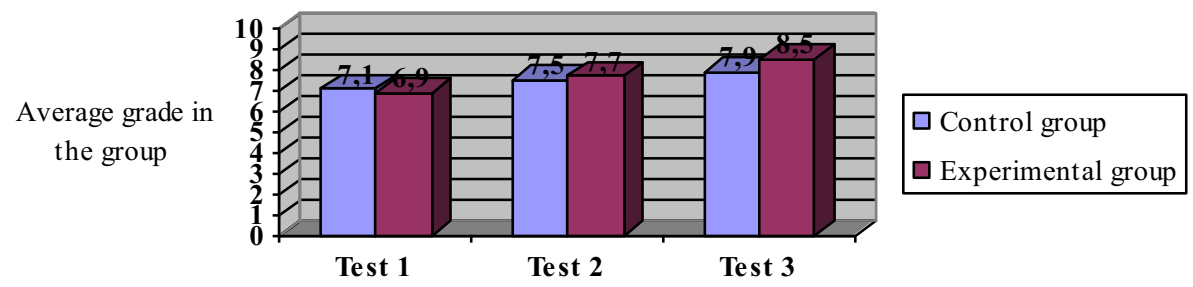

Figure 2. Assessment of students' achievements.

The histogram shows that at the start of the semester the average grade of the control group was 7.1 , which is slightly higher than the 6.9 score of the experimental group. However, at the end of the semester the experimental group showed better achievement, as the average grade or the control group was 7.9, while the average grade of the experimental group was 8.5.

The results showed that PBL contributes to more favorable conditions for learning.

\section{Conclusion}

Higher education is a driving force for innovation, economics, industry and business. It is a factor in a country's competitiveness in the global market. Innovative teaching methods and approaches at universities are aimed at developing students' potentials and to prepare them for lifelong learning. In this paper we have evaluated PBL in the context of its educational opportunities in teaching English to engineering students. The research proves that PBL motivates learning, enhances learning outcomes, improves research, and should increase career benefits.

\section{References}

1. D. Boud, G. Feletti, The challenge of problem-based learning ( $2^{\text {nd }}$ ed.), 334 (1997)

2. R.E. Mayer, Educ Psychol Rev. 8(4), 357 (1996)

3. E.De Graaf, A. Kolmos. IJEE 19(5), 657 (2003)

4. Ch.Chin1, Li-Gek Chia, Sci Educ. 88(5), 707 (2004)

5. A. Masek, S. Yamin, Int. rev. soc. sci. humanit. 2(1), 215 (2011)

6. D.H. Jonassen, W. Hung, Problem-Based Learning. Encyclopedia of the Sciences of Learning, edited by N.M. Seel, 2687 (2012)

7. E.M. Lieux. A skeptic's look at PBL. In The Power of Problem-Based Learning: A Practical 'How To' for Teaching Undergraduate Courses in Any Discipline, edited by B. Duch, S.E. Groh \& D.E. Allen, 223 (2001)

8. C. Angeli, Sci. Educ. Int. 13(3), 9 (2002)

9. K.D., Simons, J.D., Klein, T.R. Brush, JILR 15(3), 213 (2004)

10. P.A. Kirschner, J. Sweller, R.E. Clark, Educ. Psychol. 41(2), 75 (2006)

11. J.R. Savery, IJPBL 1(1), 9 (2006)

12. L. Heine. Problem Solving in a Foreign Language: A Study in Content and Language Integrated Learning. Berlin: De Gruyter, (2010)

13. D. Gijbels, F. Dochy, P. van den Bossche, M. Segers, Rev. Educ. Res. 75(1), 27 (2005)

14. J.R. Mergendoller, N.L. Maxwell, Y. Bellisimo, J. Educ. Res. 93(6), 374 (2000)

15. C.E. Hmelo-Silver, Educ Psychol Reve 16(3), 235 (2004)

16. J.C. Perrenet, P.A.J. Bouhuijs, J.G.M.M. Smits, Teach High Educ. 5(3), 345 (2010)

17. A. Klegeris, H. Hurren, Adv Physiol Educ. 35(4), 408 (2011)

18. A. EL-Shaer, H. Gaber, JEP 5(14), 74 (2014) 
Space Engineering 2016

19. M.V. Kuimova, D.A. Polyushko, (iJET). 10(1), 72 (2015).

20. A.V. Ruchina, M.V. Kuimova, D.A. Polyushko, A.E. Sentsov, Zhang Xue Jin, Procedia Soc Behav Sci. 215, 98 (2015)

21. A. Klegeris, M. Bahniwal, H. Hurren, CBE Life Sci Educ. 12(1), 73 (2013) 